\title{
The Use of Th in HTR: State of the Art and Implementation in Th/Pu Fuel Cycles
}

\author{
Guido Mazzini, ${ }^{1}$ Eleonora Bomboni, ${ }^{1}$ Nicola Cerullo, ${ }^{1,2}$ Emil Fridman, ${ }^{3}$ \\ Guglielmo Lomonaco, ${ }^{1,2}$ and Eugene Shwageraus ${ }^{4}$ \\ ${ }^{1}$ Department of Mechanical, Nuclear and Production Engineering (DIMNP), University of Pisa, CIRTEN, \\ Largo L. Lazzarino No. 2, 56126 Pisa, Italy \\ ${ }^{2}$ Energy and Environmental Conditioning Department (DIPTEM), University of Genova, Via all'Opera Pia No. 15/a, \\ 16145 Genova, Italy \\ ${ }^{3}$ Accident Analysis Division (FWSS), Forschungszentrum Dresden-Rossendorf (FZD), P.O. Box 5101 19, 01314 Dresden, Germany \\ ${ }^{4}$ Department of Nuclear Engineering, Ben Gurion University of the Negev, P.O. Box 653, 84105 Beer Sheva, Israel
}

Correspondence should be addressed to Nicola Cerullo, cerullo@docenti.ing.unipi.it

Received 28 March 2009; Accepted 1 September 2009

Recommended by Jim Kuijper

\begin{abstract}
Nowadays nuclear is the only greenhouse-free source that can appreciably respond to the increasing worldwide energy demand. The use of Thorium in the nuclear energy production may offer some advantages to accomplish this task. Extensive R\&D on the thorium fuel cycle has been conducted in many countries around the world. Starting from the current nuclear waste policy, the EU-PUMA project focuses on the potential benefits of using the HTR core as a Pu/MA transmuter. In this paper the following aspects have been analysed: (1) the state-of-the-art of the studies on the use of Th in different reactors, (2) the use of Th in HTRs, with a particular emphasis on Th-Pu fuel cycles, (3) an original assessment of Th-Pu fuel cycles in HTR. Some aspects related to Thorium exploitation were outlined, particularly its suitability for working in pebble-bed HTR in a Th-Pu fuel cycle. The influence of the Th/Pu weight fraction at BOC in a typical HTR pebble was analysed as far as the reactivity trend versus burn-up, the energy produced per Pu mass, and the Pu isotopic composition at EOC are concerned. Although deeper investigations need to be performed in order to draw final conclusions, it is possible to state that some optimized Th percentage in the initial $\mathrm{Pu} / \mathrm{Th}$ fuel could be suggested on the basis of the aim we are trying to reach.
\end{abstract}

Copyright (C) 2009 Guido Mazzini et al. This is an open access article distributed under the Creative Commons Attribution License, which permits unrestricted use, distribution, and reproduction in any medium, provided the original work is properly cited.

\section{Introduction}

Since the beginning of the nuclear age, the possibility of using Thorium as a nuclear fuel in thermal reactors appeared a very promising alternative to uranium exploitation. First of all, Thorium natural resources are three times more abundant than Uranium ones. What's more, the lower mass number of the fertile element $\left(\mathrm{Th}^{232}\right)$ entails a by far smaller build-up of high mass number TRU, which are as known responsible for the most of the long-term radiotoxicity of the nuclear waste. On the other hand, natural Thorium is composed of a single isotope $\left(\mathrm{Th}^{232}\right)$ that is not fissile, but only fertile. By a neutron capture, $\mathrm{Th}^{232}$ transmutes into $\mathrm{U}^{233}$, which is a fissile nuclide characterized by an excellent neutronic behaviour in the thermal range $[1,2]$. Hence, Th-based fuels need some amounts of $\mathrm{U}^{235}$ or Pu acting as a driver. Conversely, this kind of fertilization process produces, by $(n, 2 n)$ reaction, some $\mathrm{U}^{232}$, which is a very pernicious nuclide because of its strong $\gamma$-emitting decay daughter. Clearly, it results particularly problematic if SNF reprocessing is envisaged.

The High-Temperature gas-cooled Reactor (HTR or HTGR) is a graphite moderated, He cooled nuclear reactor that was studied and realised in the past, and that it has been recovered today in the framework of the Generation IV Initiative. HTR shows unique features due to its peculiar fuel form (TRISO-coated particles embedded in cylindrical or spherical fuel elements made of graphite) as well as to its inert coolant $(\mathrm{He})$. The gaseous coolant allows us the possibility to make the neutronics and the thermalfluiddynamics of the core substantially independent of each other. 
What's more, He is an inert coolant from the chemical point of view as well, and it does not absorb neutrons parasitically. The TRISO-coated particles permit us the possibility to reach burn-ups that are by far longer than those of LWRs (i.e., in principle up to $800 \mathrm{GWd} / \mathrm{tHM}$ without leakages of Fission Products).

Starting from these consideration and taking into account the unique characteristics of the HTR concept, it is possible to appreciate the potentialities of loading the HTR core with a Th-based fuel. First of all, reaching very long burn-ups without needing to reprocess the fuel in-between in principle enables us to exploit Th without the drawbacks previously mentioned (strong $\gamma$-rays of its daughter). Moreover, the excellent neutron economy of Thfuels is coupled with the excellent neutron economy of HTR itself (indeed, $\mathrm{He}$ and graphite are the main components of this core). Nevertheless, a driver fuel is necessary to sustain the chain reaction at BOC.

As far as the driver fuel is concerned, two main options are available, that is, enriched $\mathrm{U}$ or Pu. Although enriched $\mathrm{U}$ undoubtedly would be the best choice from the neutronic point of view, Gen. IV aims suggest Pu exploitation.

In the present paper, on the basis of some work performed by our group in the past, $\mathrm{Pu}(\mathrm{RG})$ is adopted as a driver fuel instead of HEU. Particularly, a pebble-bed HTR using Thorium along with 1st generation Plutonium has been considered, analogously to the fuel considered in the framework of the EU PUMA project [3]. This work aims at analysing the influence of the initial $\mathrm{Pu} / \mathrm{Th}$ mass ratio in the fresh fuel as far as the main neutronic and burn-up parameters are concerned: reactivity at BOC, possibility to reach very long irradiation cycles, $\mathrm{Pu}$ isotopic composition versus burn-up, energy released. Hence, the following aspects will be analysed:

(i) the state of art about the studies focusing on the use of Th in different core concepts,

(ii) the use of Th in HTRs, with a particular emphasis on Th-Pu fuel cycles,

(iii) an original assessment of Th-Pu fuel cycles in HTR, assuming, as evaluating parameters,

(a) the total energy produced,

(b) the energy produced per initial loaded $\mathrm{Pu}$,

(c) the ratio between final (discharged) and initial (loaded) Pu mass.

\section{Thorium Resources, Drawbacks of the Current Fuel Cycle, and Proliferation Concerns: A Brief Overview}

With more than 300 NPPs running worldwide, LWR is currently the most widespread nuclear reactor technology. Developed and applied successfully since the 1950s, this technology is safe, reliable, and well proven [4]. Its main drawback consists of the extremely small $U$ resource exploitation (less than 1\%), which implies what follows: (i) concerns about the limitation of $\mathrm{U}$ resource availability,

(ii) proliferation risk due to Pu content of SNF (please remember that the end of Cold War raised concerns about the proliferation risk, due to the large stockpiles of $\mathrm{Pu}$ produced by civil and military applications),

(iii) long-term toxicity of the final waste, mainly due to TRUs built up in SNF.

Indeed, an integral $\mathrm{U}$ exploitation would entail not only a huge availability of nuclear fuel resources but also a nuclear waste mainly composed of FPs instead of HMs.

The commonly mentioned design objectives of Th-based fuel cycles include the following:

(i) increasing nuclear fuel resources by breeding $U^{233}$ from thorium,

(ii) improving fuel utilization in thermal reactors,

(iii) reducing significantly the $U^{235}$ enrichment requirements,

(iv) reducing the build-up of $\mathrm{Pu}$ and of other TRU in comparison with uranium-based fuel cycles,

(v) burning Pu (RG or WP) without reprocessing, then reducing existing Pu stockpiles,

(vi) increasing the possibility to breed $\mathrm{U}^{233}$ and to incinerate long lived radiotoxic isotopes by combining the thorium-based fuel cycle with accelerator driven systems (ADS) and/or hybrid fusion driven systems.

A Th-based fuel cycle for HTR is not a new idea: the THTR experience represents and summarizes the effort made in that direction. What is more, as shown by some past work, adopting the Th fuel cycle in HTR using Pu as a driver would allow us what follows:

(i) increase of the efficiency in TRU reduction, as illustrated in Figure 1,

(ii) achieving higher fuel burn-ups.

As previously mentioned, Th is by far more abundant than $\mathrm{U}$ in the earth's crust. The primary natural Th resource [5] is monazite, which is a thorium phosphate mineral. Thorium deposits have been found in several countries [5] as shown in Figure 2. According to the US Geological Survey [5], the world thorium reserves and reserve base (resources) are shown in Figure 3.

Moreover, Th extraction technology as well as processes to recover valuable material from Th-based SNF (e.g., THOREX process) had been studied since a long time [2].

Basic researches and developments on the Th fuel cycle [1] have been conducted in many countries, and a considerable experience about Th-based fuels has been gained in power reactors worldwide (i.e., determination of material data, fabrication tests on the laboratory scale, irradiation experiments in material test reactors, use of Thbased fuel in HTRs, LWRs (including WWERs), LMFBRs, and (potentially) in MSRs, postirradiation examinations of 


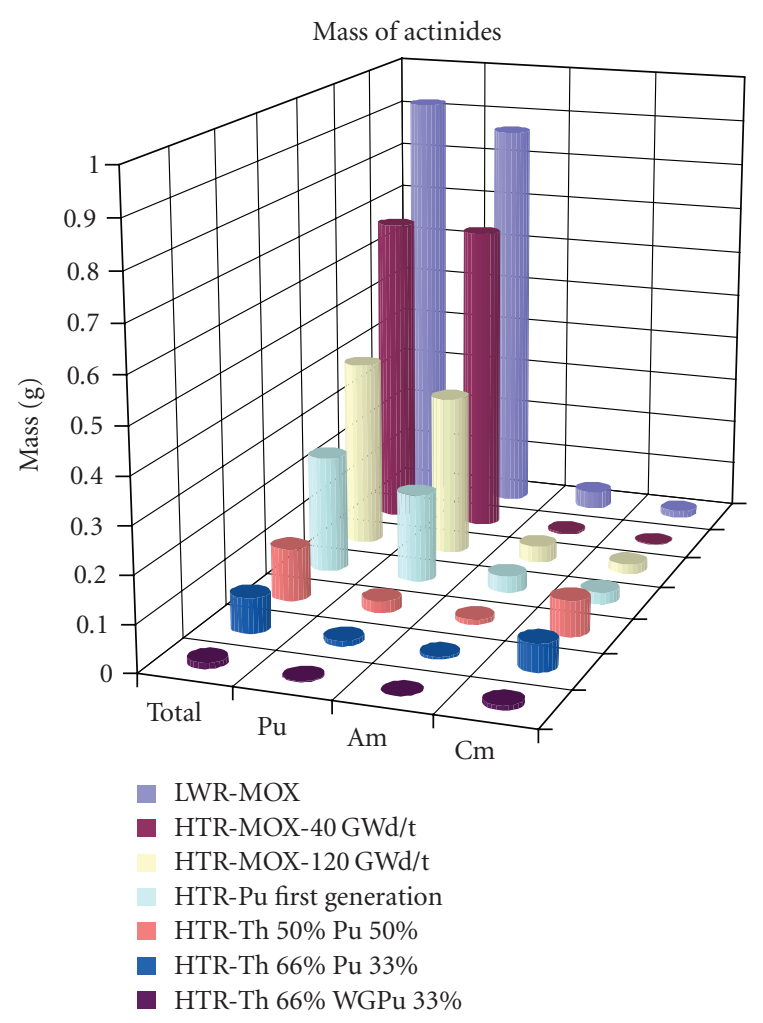

FIgUre 1: Mass of actinides at EOC starting from $1 \mathrm{~g}$ of $\mathrm{Pu}$ [4].

spent Th-based fuels, fabrication of Th-based fuel, both on pilot and semi-industrial scale (AVR)). Further activities are on-going worldwide, aiming at using Th to burn MA in both Gen-IV reactors and/or ADS.

Due to the lack of data, it seems impractical to develop meaningful cost projections [5] for any nuclear energy systems using thorium. Historical examples give some ideas of the funds that may be required. As an example, in the 1970s, Germany spent the equivalent of 500 million Euros in current money to develop a thorium fuel cycle and 2.5 billion Euros for the development of HTR. More recently, the GIF in its technology roadmap estimated that the only assessment of viability and performance of a nuclear system requires around one billion dollars (before any decision to develop and build a demonstrator, which of course would require large additional funding). The market of Th raw material [5], that is, ores or concentrates of oxide of thorium, is extremely small and limited to not-energy employments (such as high-temperature ceramics, crucibles, catalysts, welding electrodes, and some specific alloys). Additionally, the use of thorium in most of these products has been continuously decreasing, due to the burden associated with its natural radioactivity. Then, a nearly constant commercial price in the range 30-35 US $\$ / \mathrm{kg}$ [5] was published in the 1960s and 1970s, but this publication was suspended due to the progressively decreasing demand. Thus, nowadays a commercial Th price is not available. What is more, fluctuations of Th price have been minimized by a supply that by far exceeds the demand due to Th by-product build-up. That means that many countries have fairly large stockpiles of thorium that they consider as a waste.

If Th were exploited to produce electricity in the future, a Th market would develop. On the basis of what previously explained, it is reasonable to suppose that the raw material contribution to the cost of the electricity generated will remain low, comparable with or lower than that of the uranium cycle. So, from the economical point of view, the idea of using Th as a fertile material will virtually have no significant cost.

\section{A Brief Review of Thorium-Based Fuel Cycles for Different Core Concepts}

3.1. Thorium-Plutonium Fuel in LWR. The possibility of using Th-based fuels for LWR has been extensively analysed since a long time. Performances of Th- $\mathrm{U}$ and Th-Pu mixtures have been studied and compared with other more common concepts. Just to set an example, among some interesting comparisons between MOX and $\mathrm{Pu}$-Th fuels shown in [6], the case of Korean $900 \mathrm{MW}_{\mathrm{e}}$ PWR can be taken into account. Its infinite multiplication factors when fuelled by Th-based and MOX fuel assembly, respectively, were calculated by means of the HELIOS code [7]. The boron concentration was kept constant $(500 \mathrm{ppm})$. Figure 4 shows the results obtained. This example is useful to appreciate the very good neutronic behaviour of Th-based fuels, but we have to underline that there are not any advantages concerning the long-term radiotoxicity of the final waste.

Indeed, $\mathrm{Cm}^{244}$ contribution at the beginning and $\mathrm{Pu}^{239}$ and $\mathrm{Th}^{229}$ contribution successively make the radiotoxicity of the considered Th-based fuels higher than that of conventional $\mathrm{UO}_{2}$ PWR SNF.

3.2. Thorium-Uranium Fuel in CANDU Reactors. The possibility of using Th as fertile material in CANDU has been largely considered [8]. Particularly, three main types of fuel mixtures have been analysed: mixed SEU and $\mathrm{ThO}_{2}$ bundles, gadolinium-doped mixed bundles, and high burnup $\mathrm{ThO}_{2}$ bundles. The variation of lattice $k_{\text {inf }}$ as well as the change in fissile content as a function of the bundle average burn-up is shown in Figure 5, for each of these considered compositions. Physical properties of natural $\mathrm{UO}_{2}$ and natural $\mathrm{ThO}_{2}$ fuels, respectively, have been shown for comparison purposes.

Please note that the initial fissile content of the high burn-up thorium bundles has been carefully chosen so that the depletion rate of the fissile material is almost the same as the conversion rate of the fertile $\mathrm{Th}^{232}$ into fissile $\mathrm{U}^{233}$. Consequently, the reactivity and the fissile content of the high burn-up Th bundles are almost constant throughout the entire lifetime of the bundles.

3.3. Thorium-Uranium Fuel in Molten-Salt Reactors. Although the MSR core appears very different from all the other nuclear reactor concepts, the graphite-moderate MSR actually owns some features that are substantially similar to those belonging to High-Temperature Gas-Cooled Reactor (HTGR). Indeed, in both concepts the graphite moderator 


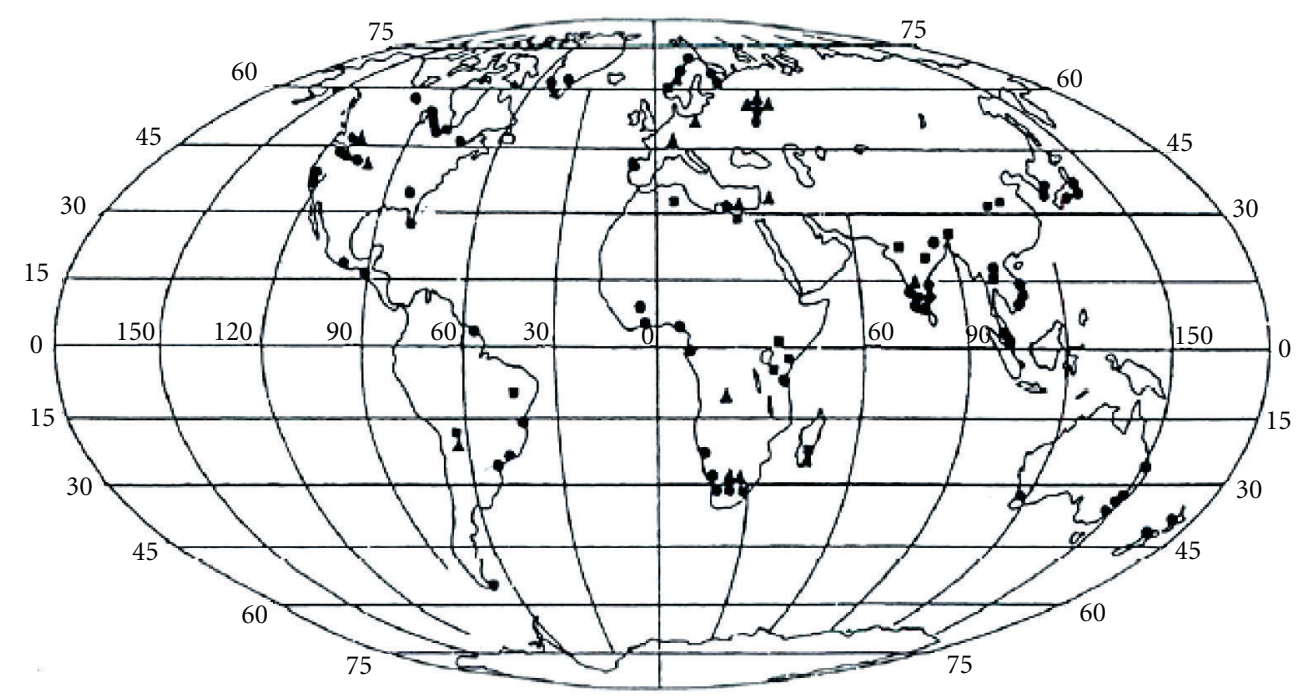

Beach \& fluviatile

Vein type thorite deposits

- Carbonatite deposits

FIgure 2: Thorium Deposits in the World [5].

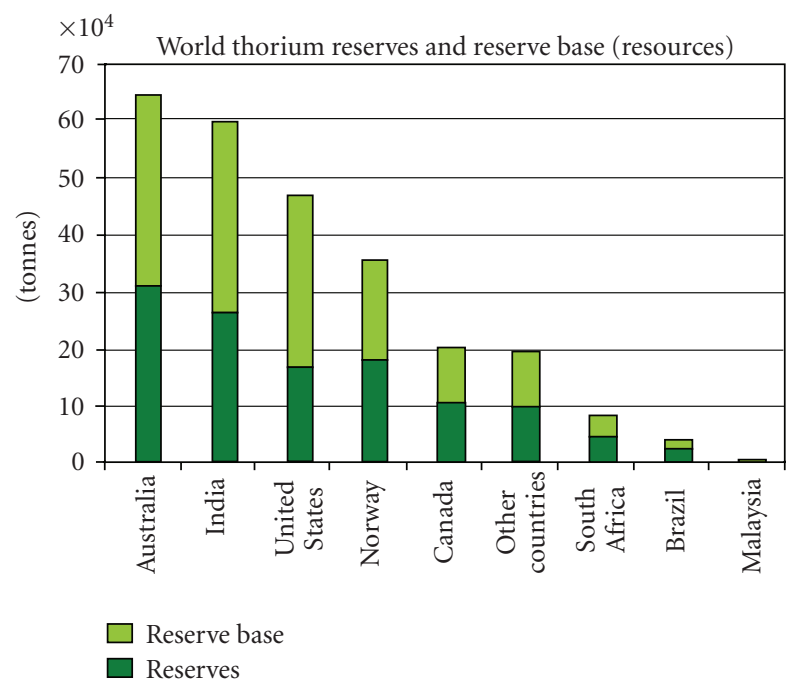

Figure 3: The World Thorium Reserves and Reserve Base [5].

is at an average temperature between $600-700^{\circ} \mathrm{C}$, a Th- $\mathrm{U}$ mixture can be adopted as a fuel, and the moderation ratios are very close to each other. Therefore, a large part of the thermal reactor technology (and, particularly, of HTGRs) is directly applicable to this kind of MSR design. Therefore, nuclear data and methods for calculating neutron fluxes, reactivity temperature coefficients, and so on developed for HTGR can be applied for the MSR design, even though notnegligible differences remain. Some examples of applications of Th-based fuel in MSR could be found in $[9,10]$.

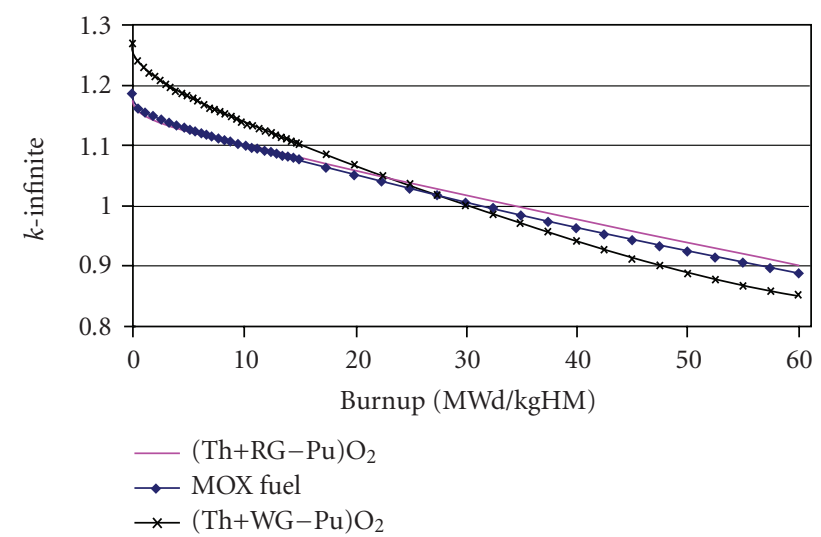

FIgURE 4: $k$-infinite as a function of burn-up [6].

\section{The Use of Thorium in HTR}

4.1. Preliminary Considerations on TH-PU Cycle in HTR. The reduction of $\mathrm{Pu}$ stockpiles as well as the discharge of a nuclear waste that is very poor from the $\mathrm{Pu}$ content point of view is among the main goals of the current nuclear research. Then, Th-Pu-based fuels have to be considered as promising candidates to reach these objectives. What is more, the possibility of very long irradiation cycles allowed by HGTR cores has on the other hand to be taken into account as well. These considerations justify the efforts to develop Th$\mathrm{U}$ and Th-Pu fuel cycles in HTGR core concepts [11-15]. Among the others, a few researches on Th-Pu fuel cycle in HTR were performed by our group in the past $[4,16]$. 


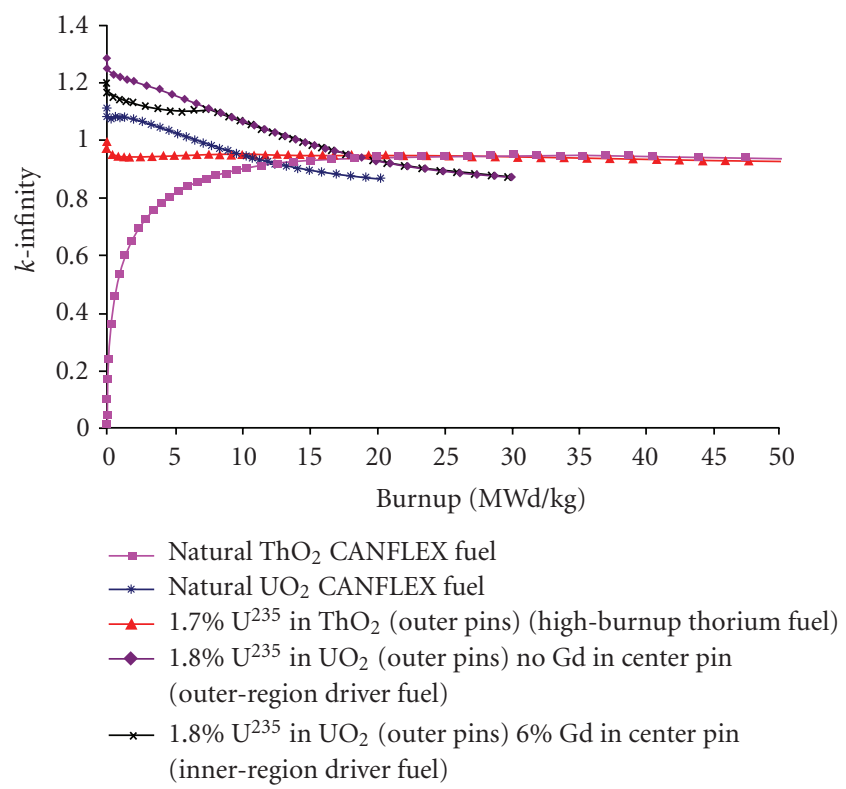

FIgURE 5: $k_{\text {inf }}$ as a function of burn-up in CANDU [8].

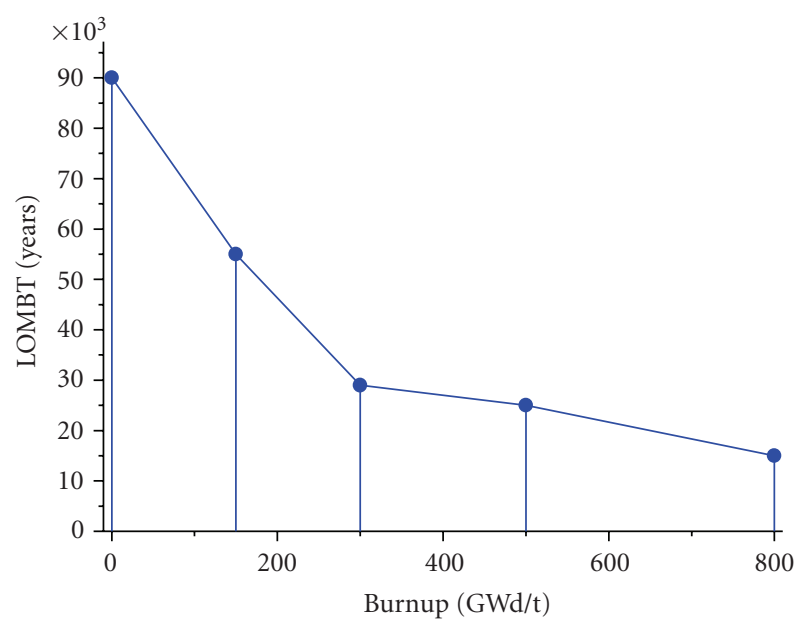

Figure 6: LOMBT versus Burn-up (2/3 Th - 1/3 Pu) [4].

The results shown in [4] lead us to draw some considerations concerning the behaviour of highly-burned (i.e., up to $800 \mathrm{GWd} / \mathrm{tHM}$ ) Thorium-Plutonium fuel. Figure 6 reports the Level Of Mine Balancing Time (LOMBT) trend as a function of burn-up: it is clear that the best choice in terms of radiotoxicity reduction is to reach a burn-up that is as high as possible. This results is mainly due to a progressively larger $\mathrm{Pu}$ consumption.

Considering the rather long LOMBT of a typical LWR SNF, the reduction of the final radiotoxicity and of the total amount of waste is of course a key issue. Looking at this latter, the actinide mass reduction in the final waste to be stored in a permanent repository is another very attractive characteristic of HTRs (Figure 7).

Despite a larger production of curium isotopes (especially $\mathrm{Cm}^{244}$ ), it is clearly shown by Figure 8 that reaching

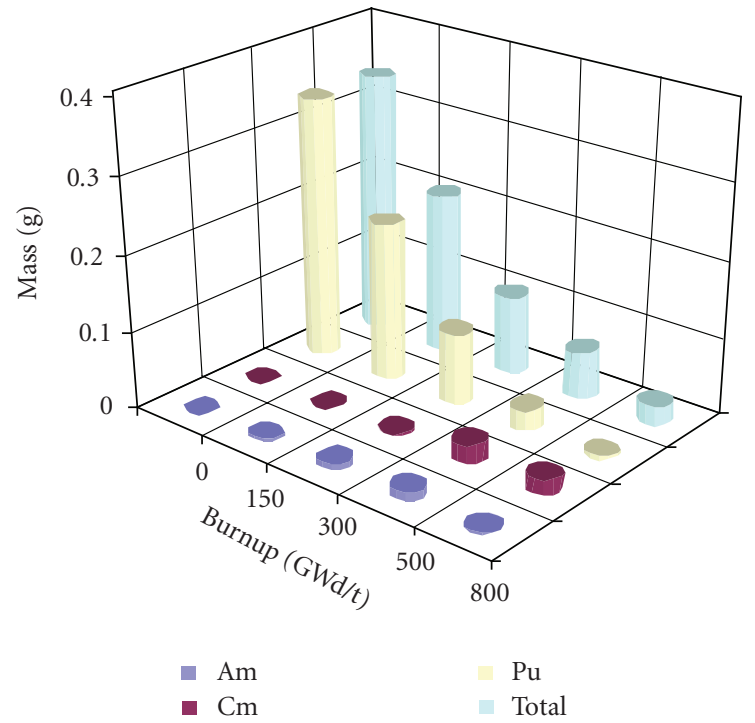

FIgURE 7: Masses of actinides versus fuel discharge burn-up (2/3 Th $-1 / 3 \mathrm{Pu}$ ) [4].

high burn-ups allows us to strongly reduce the masses of dangerous actinides.

The main results of [4] are summarized in Table 1.

4.2. The PUMA Project. Recently, Th as fuel for HTR has been considered, among the others, in the framework of the EU PUMA project [5]. Starting from the current legacy of nuclear waste as well as from the (V)HTR good capabilities of Pu burning, the PUMA activities focus on core physics investigations, in order to further demonstrate the potential benefits of using the HTR core as a Pu/MA transmuter (as known, annually a $1000 \mathrm{MW}_{\mathrm{e}}$ PWR produces about 30 tons of SNF (burn-up around $30 \mathrm{GWD} / \mathrm{tHM}$ ) with the following average composition [7]: $94 \% \mathrm{U}^{238}, 1 \% \mathrm{U}^{235}, 1 \%$ $\mathrm{Pu}, 0.1 \% \mathrm{MA}(\mathrm{Np}, \mathrm{Am}$ and $\mathrm{Cm}), 3-4 \% \mathrm{FP})$. Moreover, as (V)HTR Pu/MA transmuters are foreseen to operate in a global system of reactor designs and fuel cycle facilities, fuel cycle studies and socioeconomic/environmental assessments have been carried out. The PUMA consortium gathers 16 organisations from 9 countries (BE, DE, FR, IT, NL, PL, SE, UK, USA), including research organisations, leading nuclear engineering and fuel cycle firms, a fuel manufacturer, a utility, universities and institutes, and consultancy SMEs. The work carried out in the framework of PUMA represents part of the EURATOM contribution to the GIF [9].

Among the other activities of PUMA project, a deep burn-up fuel cycle strategy using the Th-Pu fuel in PBMR reactor $[8]$ has been investigated.

Many of the data used in the following sections are based on PUMA project findings.

\section{Calculations and Results}

5.1. Calculation Parameters and Models. In this research, on the basis of the advantages outlined in previous paragraphs, 
TABLE 1: Summary of obtained results $\left(k_{\infty} \sim 1.05\right)[4]$.

\begin{tabular}{|c|c|c|c|c|c|}
\hline Fuel/Pebble & EFPD & LOMBT & Energy/Pebble & $\mathrm{Pu}_{\text {out }} / \mathrm{Pu}_{\text {in }}$ & $\mathrm{TRN}^{*} / \mathrm{Pu}_{\text {in }}$ \\
\hline $1 \mathrm{~g} \mathrm{Pu} 1$ st gen. & 600 & 43000 & $51.8 \mathrm{GJ}$ & $32.9 \%$ & $37.6 \%$ \\
\hline $1.5 \mathrm{~g} \mathrm{Pu}$ 2nd gen. & 645 & 35000 & $55.7 \mathrm{GJ}$ & $46.4 \%$ & $54.9 \%$ \\
\hline $1 \mathrm{~g} \mathrm{Pu} 1 \mathrm{st}+2 \mathrm{~g} \mathrm{Th}$ & 705 & 34000 & $60.9 \mathrm{GJ}$ & $26.6 \%$ & $32.8 \%$ \\
\hline
\end{tabular}

NOTE: ${ }^{*} \mathrm{TRN}=\mathrm{Pu}_{\mathrm{out}}+\mathrm{Am}+\mathrm{Cm}$.

TABle 2: $(\mathrm{Pu}-\mathrm{Th}) \mathrm{O}_{2}$ fuel general characteristics in accordance with PUMA Project $[10,11]$.

\begin{tabular}{ll}
\hline Description & Value \\
\hline $\begin{array}{l}\text { Fuel pebble } \\
\text { Fuel pebble outer radius }\end{array}$ & $3.0 \mathrm{~cm}$ \\
$\begin{array}{l}\text { Thickness of fuel free zone } \\
\text { Total heavy metal loading per fuel } \\
\text { pebble }\end{array}$ & $0.5 \mathrm{~cm}$ \\
$\begin{array}{l}\text { Matrix density } \\
\text { Packing fraction in pebble bed }\end{array}$ & $1.0 \mathrm{~g}$ \\
$\begin{array}{l}\text { Coated particle } \\
\text { Kernel Coating Material }\end{array}$ & $61 \%$ \\
Layer thickness & $\mathrm{C} / \mathrm{C} / \mathrm{SiC} / \mathrm{C}$ \\
Layer densities & $90 / 40 / 35 / 40 \mu \mathrm{m}$ \\
$\begin{array}{l}\text { Fuel kernel } \\
\text { Fuel kernel diameter }\end{array}$ & $1.05 / 1.90 / 3.18 / 1.90 \mathrm{~g} / \mathrm{cm}^{3}$ \\
Kernel material type & \\
Th-oxide density & $200 \mathrm{micron}$ \\
Pu-oxide density & $\left(\mathrm{Pu}-\mathrm{Th}^{3} \mathrm{O}_{2.0}\right.$ \\
\hline
\end{tabular}

TABLE 3: Composition of 1st generation $\mathrm{Pu}[10,11]$.

\begin{tabular}{lc}
\hline Pu isotopes & First Generation (weight \%) \\
\hline 238 & 2.59 \\
239 & 53.85 \\
240 & 23.66 \\
241 & 13.13 \\
242 & 6.78 \\
\hline
\end{tabular}

we investigated the main neutronic characteristics related to the utilization of Th as fertile material in PBMR loaded with a Pu/Th fuel, by means of MCNP5 [17] code.

The model used to perform these analyses is described in the following lines.

In our simulations Pu-RG (i.e., Plutonium produced during irradiation of $\mathrm{UO}_{2}$ fuel in a typical LWR) has been chosen as driver fuel. In principle, Pu-RG is not suitable for proliferation purposes, due to its high content of even isotopes $\left(\mathrm{Pu}^{238}, \mathrm{Pu}^{240}, \mathrm{Pu}^{242}\right)$, which are characterized by a high spontaneous fission rate and, at least in the case of $\mathrm{Pu}^{238}$, by a high decay heat as well. Th content in the considered pebble has been varied from $0 \%$ to $100 \%$ of the HM constituting the fuel. Table 2 shows the main parameters of the analyzed PBMR fuel elements, while Table 3 shows the $\mathrm{Pu}-\mathrm{RG}$ (1st gen. $\mathrm{Pu}$ ) isotopic vector.

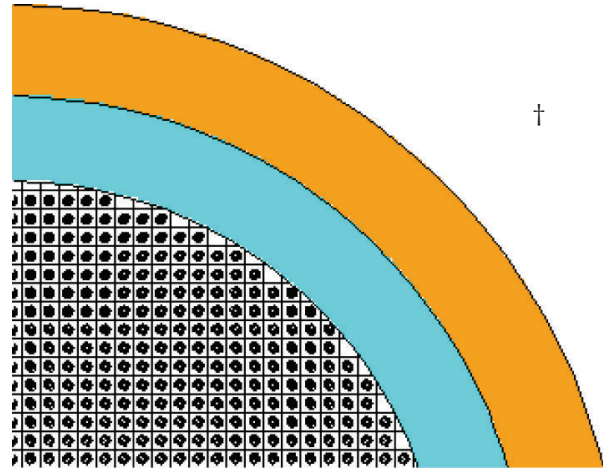

Figure 8: MCNP model without cut CPs [16].

Additionally, we fixed the following calculation parameters.

(i) An infinite lattice of stochastically arranged pebble has been considered for each fuel composition, by modelling a single sphere (with the He gap associated) with white boundary conditions.

(ii) Each of the considered pebbles contains $2 \mathrm{~g} \mathrm{HM}$ $(\mathrm{Pu} / \mathrm{Th})[5]$.

(iii) Due to the lack of data and for the sake of simplicity, the density of $(\mathrm{Pu}, \mathrm{Th}) \mathrm{O}_{2}$ fuel (with $\mathrm{Th}$ content varying from $0 \%$ to $100 \%$ of $\mathrm{HM}$ ) has been assumed as varying linearly from the density of $\mathrm{PuO}_{2}$ kernels $\left(10.89 \mathrm{~g} / \mathrm{cm}^{3}[12]\right)$ to the density of $\mathrm{ThO}_{2}$ kernels $\left(9.55 \mathrm{~g} / \mathrm{cm}^{3}[13]\right)$, as a function of the Th fraction.

(iv) Geometric error reduction: the pebbles have been modelled as actual as possible (Figure 15), also on the basis of the results obtained in [16].

(v) No temperature profile inside the pebble: the temperature is uniform everywhere and equal to $1200 \mathrm{~K}$.

(vi) The cross section libraries used in this work are JEFF3.1 [18].

(vii) Helium Gap: according to the average packing fraction of the PBMR core (61\% [8]) the helium gap has been explicitly modelled.

Figure 8 shows an $x-y$ view of the pebble model adopted to perform these calculations. Please note that clipped CPs along the boundary of the fuelled zone have been eliminated.

5.2. Preliminary Results. The variation of the $k$-infinite at BOC as a function of Th percentage is shown in Figure 9. 


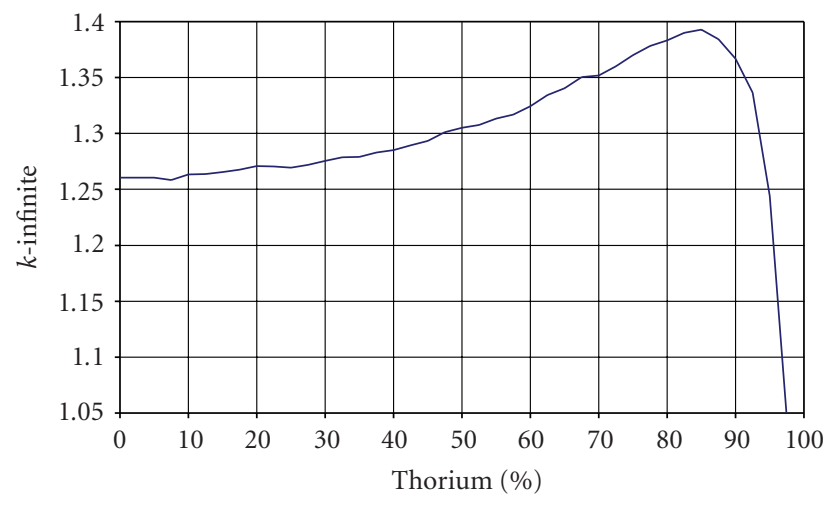

Figure 9: Variation of $k$-infinite at BOC as a function of Th content.

Analysing the trend of this curve, we can note that some trends can be recognised on the basis of Th content:

(i) $0 \% \leq \mathrm{Th} \%<10 \%$ : the $k$-infinite value remains near 1.26 (flat trend);

(ii) $10 \% \leq \mathrm{Th} \%<30 \%$ : a slightly positive gradient is shown (the $k$-infinite increases from 1.26 to 1.27 );

(iii) $30 \% \leq \mathrm{Th} \%<84.5 \%$ : the value of $k$-infinite increases linearly from $\sim 1.27$ and to $\sim 1.39$;

(iv) $84.5 \% \leq \mathrm{Th} \%<100 \%$ : the $k$-infinite decreases from the peak at $84.5 \%\left(k_{\infty}=1.39274, \sigma=0.00154\right)$ to 1 .

In order to complete this analysis, the fuel behaviour as a function of burn-up has to be considered. All the following burn-up calculations has been performed by means of the BGCore code [19].

5.3. BGCore Code. The burn-up calculations were performed with BGCore. BGCore is a software package for comprehensive computer simulation of nuclear reactor systems and their fuel cycles. It consists of a number of modules:

(i) 3-dimensional coupled neutronic and thermal hydraulic module, which calculates the reactor core criticality, as well as the core power and temperature distributions; only steady state core analysis is considered at this stage of the BG-Core package development; no thermal feedback features were used in this analysis;

(ii) fuel depletion and decay module, which calculates the fuel isotopic composition;

(iii) auxiliary modules for basic data processing and management.

5.4. $k$-Effective versus $k$-Infinite Burn-Up Calculations Comparison. The "real" $k$-effective in PBMR depends not only from the material and the core geometry, as in LWR reactors, but also from a random contribution due to pebbles recirculation [20]. Then, a not-negligible approximation is introduced by calculating the $k$-effective fixing the pebble arrangement in the core. In addition, even adopting this

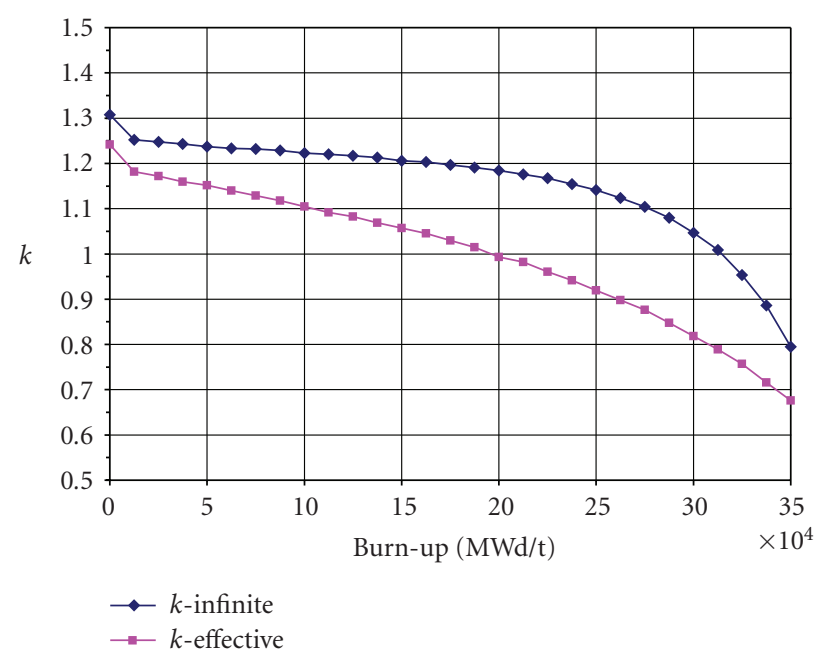

FIGURE 10: $k$-infinite and $k$-effective trends as a function of burn-up (expressed in $\mathrm{MWd} / \mathrm{tHM}$ ).

approximation, $k$-effective calculations are quite expensive form the computational point of view.

Hence, in order to roughly estimate the differences between $k$-effective model (i.e., fixed geometry) and $k$ infinite one, we made a preliminary evaluation, performing two burn-up calculations with a representative fuel composition. Particularly, a fuel composed of $50 \%$ Th and $50 \% \mathrm{Pu}$ was adopted. This choice was also due to the fact that the results obtained can be directly compared with an independent calculation performed by FZJ [15].

Figure 10 and Table 4 show our main results.

Thus, we can outline some considerations.

(i) If we adopt $k$-inf $=1$ as exit conditions for the burnup calculations, we obtain a reasonable discharge burnup (comparable to that one we can obtain in a real pebble-bed HTR for a discharged pebble with the same initial composition).

(ii) The shape of $k$ trends versus burn-up are quite similar.

(iii) The ratios (OUT/IN) among Pu isotopes have (in the two cases) the same order of magnitude.

(iv) The total ratio $\mathrm{Pu}_{\text {out }} / \mathrm{Pu}_{\text {in }}$ in the two cases considered is comparable.

(v) Finally the discharge burn-up obtained in the FZJ calculation is quite similar $(\Delta \sim 5 \%)$ to that we obtained assuming $k=1$ as exit condition for the $k$-infinite calculation (see Table 5).

For the reasons described above and because of the kind of study (preliminary parametric evaluation), we performed the calculations shown in the following paragraphs using a simplified $k$-infinite model instead of a $k$-effective one.

5.5. Burn-Up Results. As anticipated above, we analysed some $\mathrm{Th} / \mathrm{Pu}$ compositions by means of BGCore, in order to assess the fuel behaviour as a function of burn-up. The basic assumptions for these calculations are the following: 
TABLE 4: $\mathrm{Pu}_{\text {out }} / \mathrm{Pu}_{\text {in }}$ for $k$-infinite and $k$-effective models.

\begin{tabular}{lrrrrrr}
\hline & $\mathrm{Pu}^{238}{ }_{\text {out }} / \mathrm{Pu}^{238}{ }_{\text {in }}$ & $\mathrm{Pu}^{239}{ }_{\text {out }} / \mathrm{Pu}^{239}{ }_{\text {in }}$ & $\mathrm{Pu}^{240}{ }_{\text {out }} / \mathrm{Pu}^{240}{ }_{\text {in }}$ & $\mathrm{Pu}^{241}{ }_{\text {out }} / \mathrm{Pu}^{241}{ }_{\text {in }}$ & $\mathrm{Pu}^{242}{ }_{\text {out }} / \mathrm{Pu}^{242}$ in & $\mathrm{Pu}^{\text {tot }}{ }_{\text {out }} / \mathrm{Pu}^{\text {tot }}{ }_{\text {in }}$ \\
\hline$k$-infinite & $43,76 \%$ & $5,46 \%$ & $23,25 \%$ & $48,63 \%$ & $189,23 \%$ & $28,64 \%$ \\
$k$-effective & $42,57 \%$ & $9,05 \%$ & $53,65 \%$ & $55,51 \%$ & $185,46 \%$ & $38,38 \%$ \\
\hline
\end{tabular}

TABle 5: Comparison between $k$-infinite model and FZJ [15] results.

\begin{tabular}{lll}
\hline $\begin{array}{l}\text { Heavy metal load and } \\
\text { composition per pebble }\end{array}$ & $\begin{array}{l}\text { FZJ calculation-discharge } \\
\text { burn-up [MWd/kgHM] }\end{array}$ & $\begin{array}{l}k \text {-infinite calculation-discharge } \\
\text { burn-up [MWd/kgHM)] }\end{array}$ \\
\hline $1 \mathrm{~g} \mathrm{Pu}, 1.0 \mathrm{~g}$ Th-232 & 332.38 & 314.42 \\
\hline
\end{tabular}

(i) times steps of 25 days at full power,

(ii) power per pebble fixed at $1 \mathrm{~kW}$,

(iii) uniform fuel temperature $(1200 \mathrm{~K})$ inside the pebble,

(iv) discharge burn-up is set at the time when $k$-infinite becomes equal to 1 , to give a preliminary estimation of the theoretical nuclear burn-up.

(As already underlined, please note that the real PBMR will not be fuelled with pebbles at the same burn-up level, but with a mixture of pebbles at different burn-ups [21]: the real discharge burn-up in principle could be extremely high [21], i.e., up to twice the assumed discharge burnup. On the other hand, we calculated the $k$-infinite instead of $k$-effective (so we have not took into account leakages and effects related to the structures surrounding the core)).

The results concerning $k$-inf are summarized in Figure 11. Please note that all the standard deviations are around $100 \mathrm{pcm}$, which is the value commonly accepted in this kind of calculation by means of MC codes.

As anticipated in the introduction, we evaluated the fuel behaviour on the basis of the following parameters:

(i) the total energy produced,

(ii) the energy produced per initial Pu mass,

(iii) the ratio between final (discharged) and initial (loaded) masses for the $\mathrm{Pu}$ isotopes.

The obtained results are shown in Figures 12-19.

Starting from the previous figures, it is possible to highlight some interesting features.

(i) $k$-infinite at BOC increases with initial Th content (Figure 11).

(ii) Regardless of the initial fuel composition, $k$-infinite versus burn-up curves show the same qualitative trend (Figure 11).

(iii) Regardless of the initial fuel composition, the only $\mathrm{Pu}$ isotope increasing from $\mathrm{BOC}$ to $\mathrm{EOC}$ is $\mathrm{Pu}^{242}$ (Figure 18).

(iv) In order to achieve a reasonably high burn-up (i.e., $100 \mathrm{GWd} / \mathrm{tHM}$ at least), initial Th concentration should not be larger than $80 \%$ (Figure 11).

(v) The presence of $30 \% \mathrm{Pu}$ in fresh fuel is the threshold to obtain a discharge burn-up higher than 190 GWd/tHM (Figure 11).

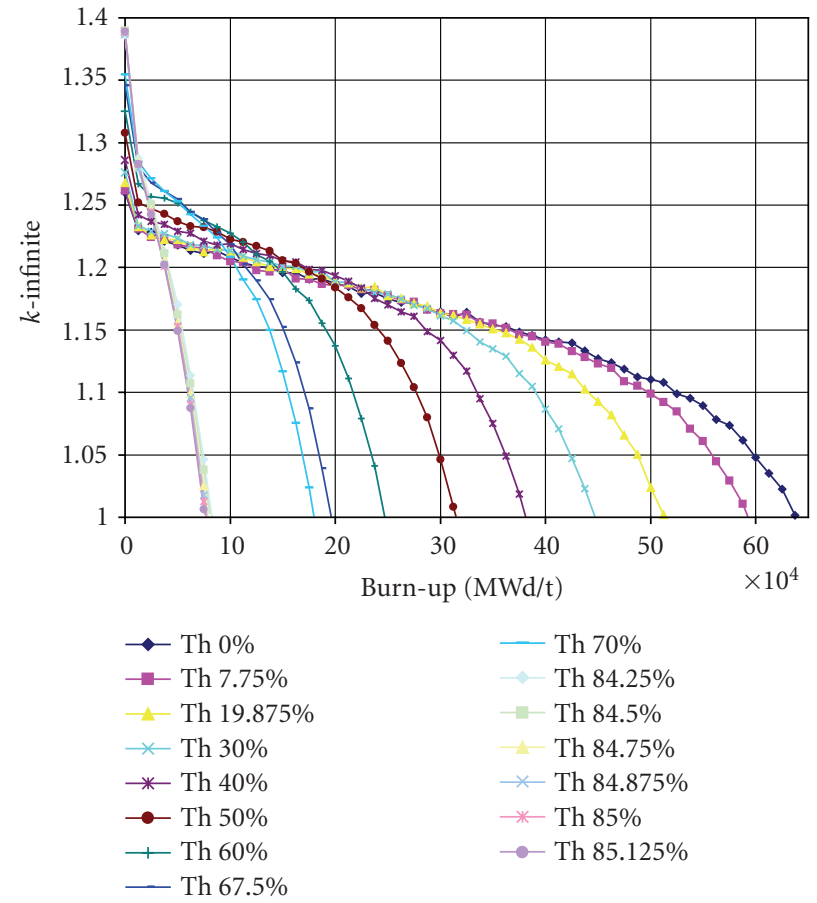

FIGURE 11: $k$-infinite variation as a function of burn-up (expressed in $\mathrm{MWd} / \mathrm{tHM}$ ).

(vi) Increasing Th fraction entails an even smaller $\mathrm{Pu}$ consumption per unit energy, although this trend is not monotonous (Figure 19). Up to a Th concentration not higher than $70 \%$, the smallest fissile $\mathrm{Pu}$ consumption per unit energy corresponds to an initial Th percentage that is equal to $67.5 \%$ (Figures 15 and 17).

(vii) $\mathrm{Up}$ to a $\mathrm{Pu}$ concentration equal to $70 \%$, we have the largest $\mathrm{Pu}$ mass at EOC, if the initial Th content is 67.5. Then, this composition corresponds to the best exploitation of Th itself. What is more, a smaller $\mathrm{Pu}$ consumption means a smaller production of Am and $\mathrm{Cm}$, which generally build up in HTR cores. This behaviour can be considered positive or negative depending on what we are aiming at.

(viii) All the SNF compositions here obtained are strongly proliferation resistant, because of their high content in even Pu nuclides (Figures 14, 16, and 18). 


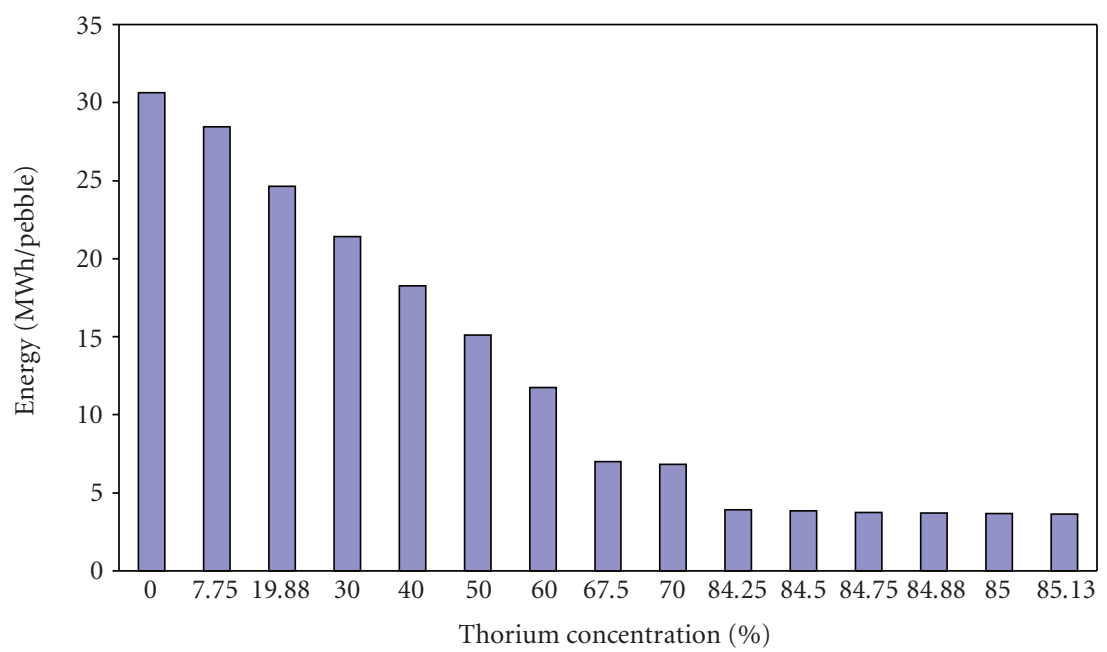

Figure 12: Produced energy (from BOC up to the time at which $k$-infinite becomes equal to unity) versus Th concentration.

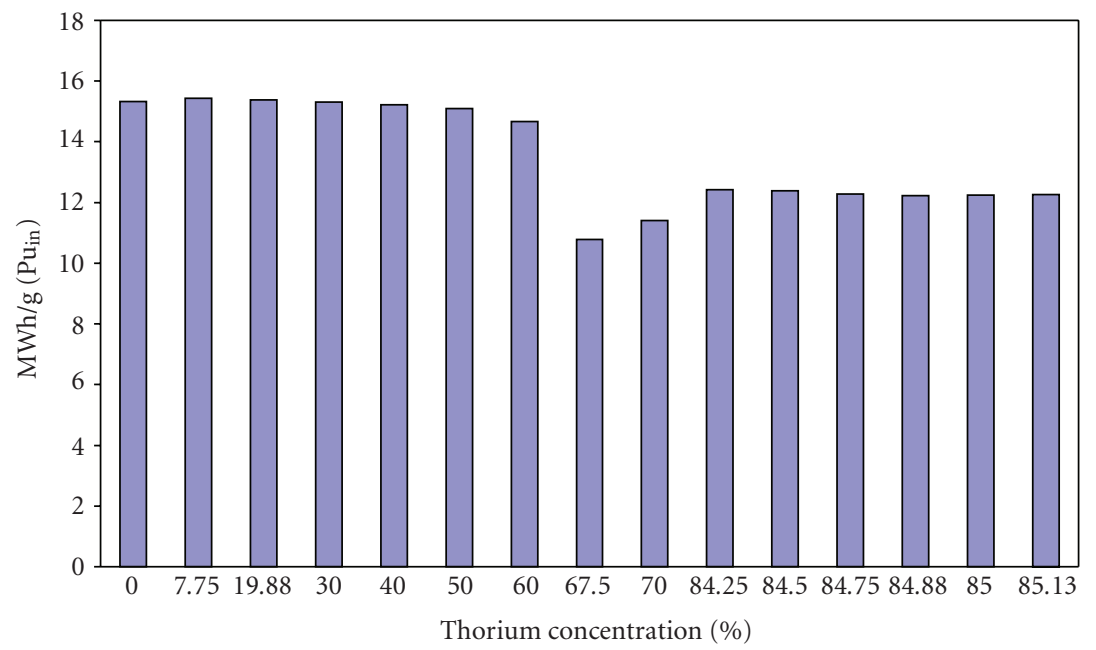

FIGURE 13: Energy produced per $\mathrm{g}_{\mathrm{Pu}}{ }_{\mathrm{in}}$ versus Th concentration.

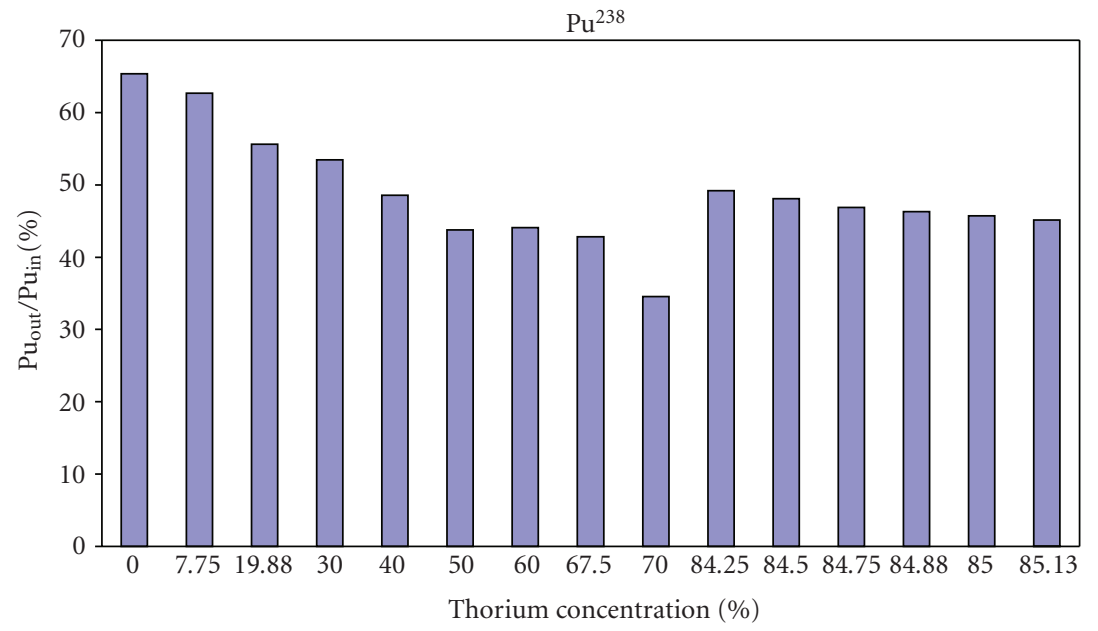

Figure 14: $\mathrm{Pu}^{238}{ }_{\text {out }} / \mathrm{Pu}^{238}$ in versus Th concentration. 


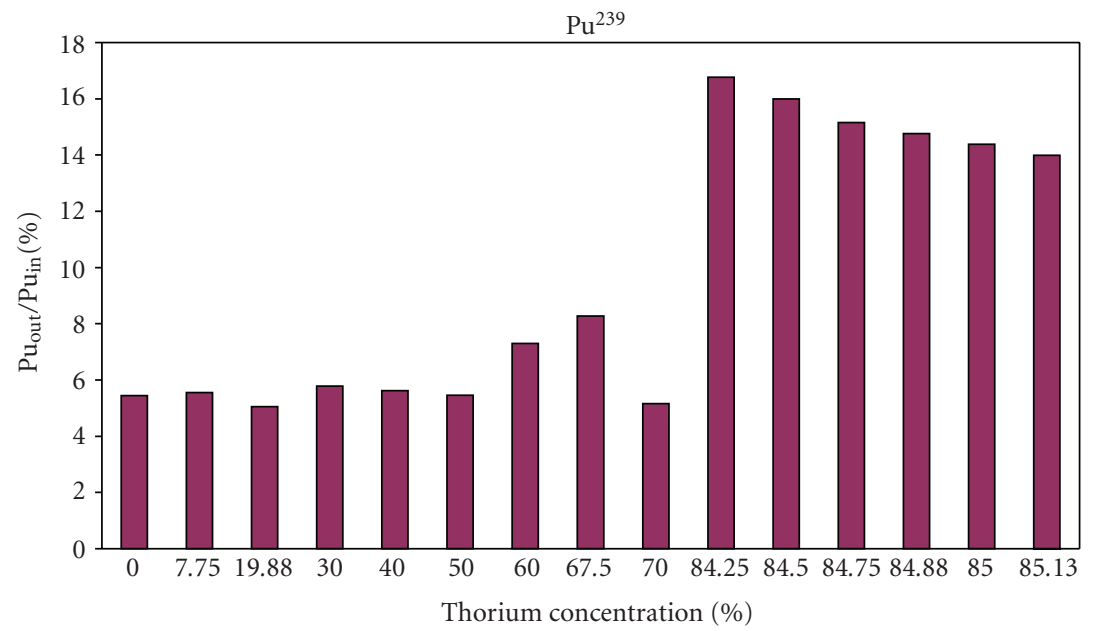

Figure 15: $\mathrm{Pu}^{239}{ }_{\text {out }} / \mathrm{Pu}^{239}{ }_{\text {in }}$ versus Th concentration.

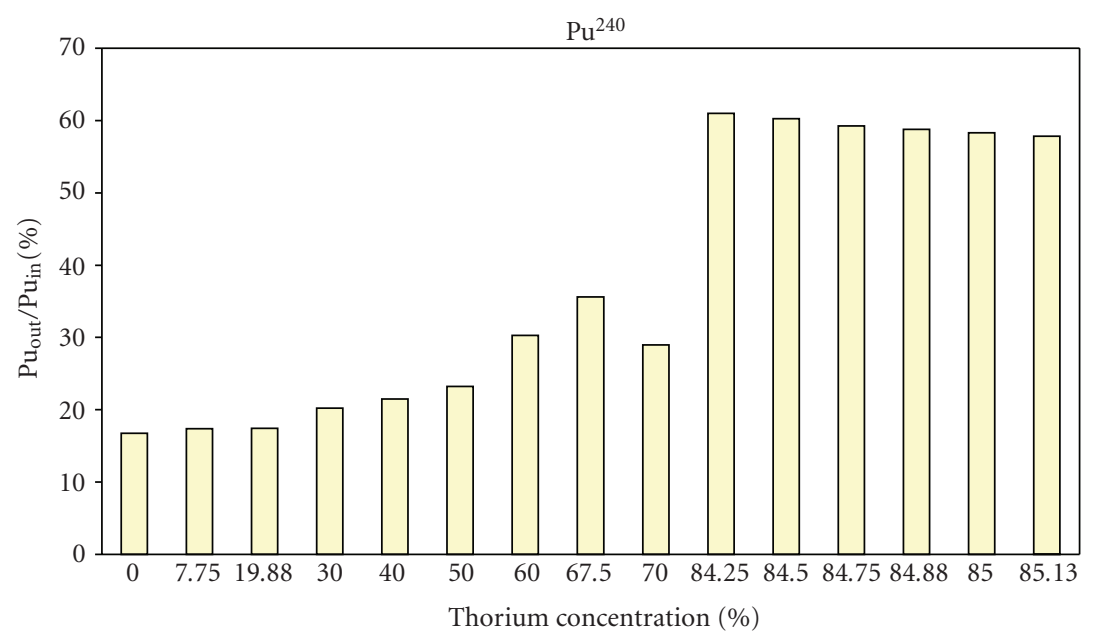

Figure 16: $\mathrm{Pu}^{240}{ }_{\text {out }} / \mathrm{Pu}^{240}$ in versus Th concentration.

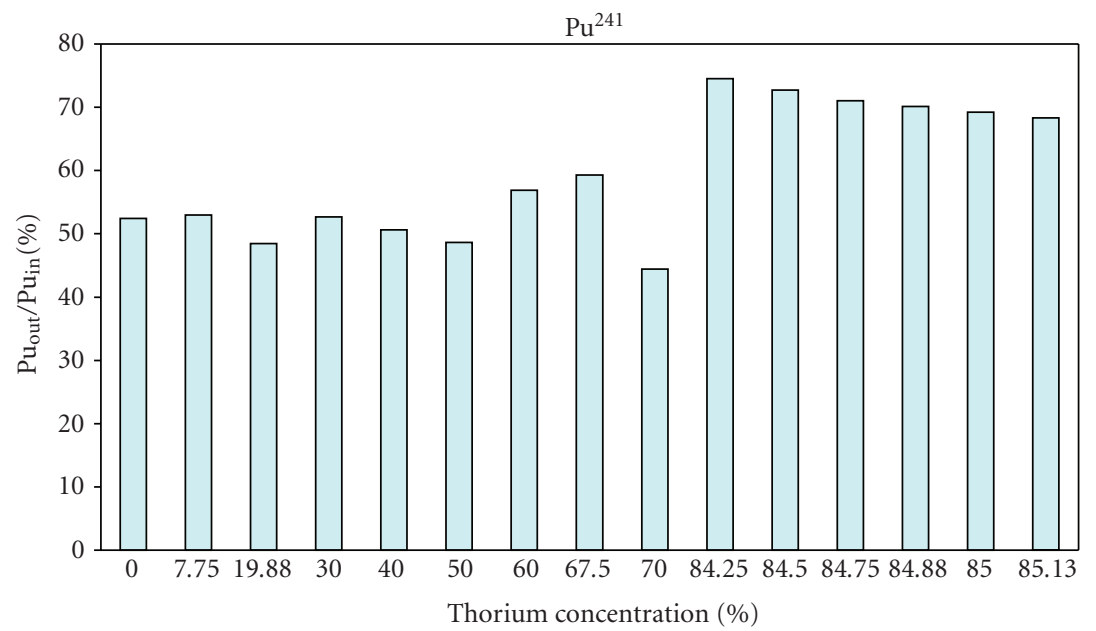

FigUre 17: $\mathrm{Pu}^{241}{ }_{\text {out }} / \mathrm{Pu}^{241}$ in versus Th concentration. 


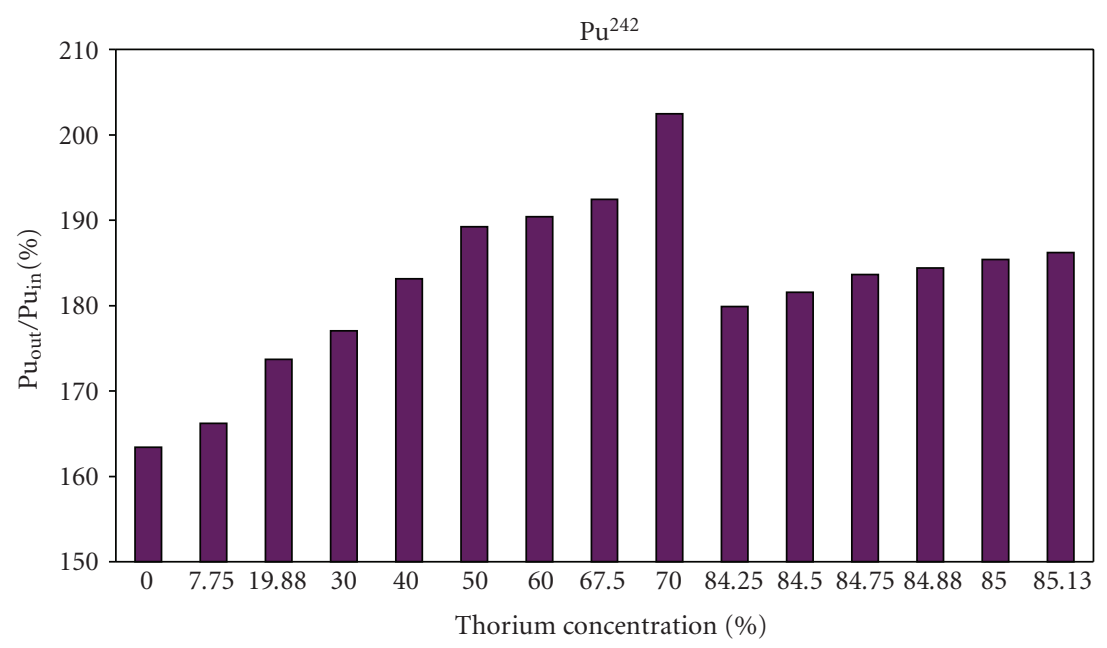

Figure 18: $\mathrm{Pu}^{242}{ }_{\text {out }} / \mathrm{Pu}^{242}$ in versus Th concentration.

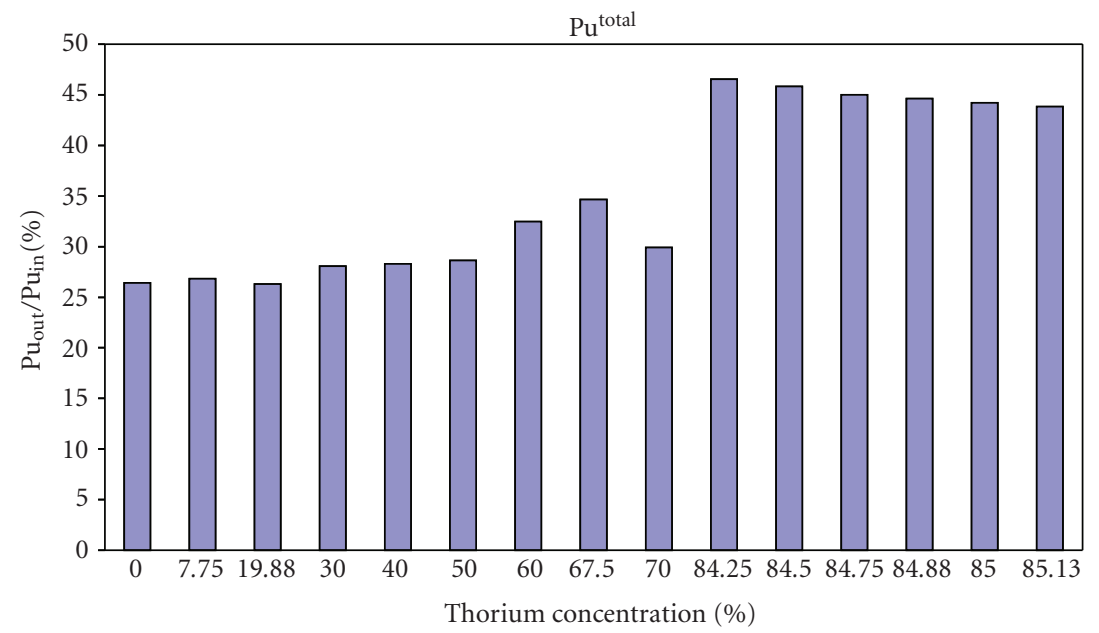

Figure 19: $\mathrm{Pu}^{\text {tot }}{ }_{\text {out }} / \mathrm{Pu}^{\text {tot }}$ in versus Th concentration.

(ix) Except for $\mathrm{Pu}^{238}$ and $\mathrm{Pu}^{242}$, there are not significant differences changing the Th initial concentration from $0 \%$ to $50 \%$. That means, up to $50 \%$ in $\mathrm{Pu}$ content, that Th contribution to energy production is substantially low (Figure 13). Conversely, Th content influences in a negative way the possibility of reaching higher burn-ups (Figure 11). Above the point corresponding to $50 \%$ initial Th percentage, the behaviour is much more determined by Th content. The highest Th exploitation per single cycle is reached with $67.5 \%$ initial Th content. That entails also a lower transmutation rate of $\mathrm{Pu}$ in $\mathrm{Am}$ and $\mathrm{Cm}$ (positive from the long-term radiotoxicity point of view).

\section{Conclusions}

Some aspects related to Thorium exploitation were outlined, with a particular emphasis on its suitability for working in pebble-bed HTRs as a fertile element in a Th-Pu fuel cycle.
That is a promising kind of fuel, which was also considered in the framework of the EU PUMA project. Particularly, the influence of the $\mathrm{Th} / \mathrm{Pu}$ weight fraction at BOC in a typical HTR pebble was analysed as far as the reactivity trend versus burn-up, the energy produced per Pu unit mass, and the $\mathrm{Pu}$ isotopic composition at EOC are concerned. On the basis of a preliminary comparative analysis (between a $k$-infinite and a $k$-effective model) and because of the kind of assessment presented here (i.e., a preliminary parametric evaluation), we chose a (simplified) $k$-infinite model instead of a $k$-effective one to perform our calculations.

Some general trends depending on the initial Th content can be recognized, and particularly the following.

(i) $k$-infinite versus burn-up shows the same qualitative trend regardless of the initial Th content (Figure 11).

(ii) $k$-infinite at $\mathrm{BOC}$ increases with initial Th content in a proportional way, and its decrease is as sharp as the Th content itself is high (Figure 11). That may make the reactivity control somewhat difficult. 
(iii) The final burn-up increases with initial Th percentage decrease (Figure 11). If the content of Th is larger than $80 \%$, the system becomes subcritical after less than $100 \mathrm{GWd} / \mathrm{tHM}$ burn-up (Figure 11).

(iv) Up to a Th concentration not higher than $70 \%$, the smallest fissile $\mathrm{Pu}$ consumption per unit energy corresponds to an initial Th percentage that is equal to $67.5 \%$ (Figures 15 and 17 ).

(v) All Pu nuclides except to $\mathrm{Pu}^{242}$ decrease from BOC to EOC regardless of the initial Th content (Figure 15).

(vi) The point corresponding of a minimum in Pu consumption per unit energy produced (i.e., $67.5 \% \mathrm{Th}$, Figure 13) corresponds to the highest Th exploitation and to the lowest transmutation of $\mathrm{Pu}$ into heavier nuclides $\left(\mathrm{Pu}^{242}, \mathrm{Am}\right.$, and $\left.\mathrm{Cm}\right)$.

These results suggest us that there is not a "best" composition for the PBMR Pu/Th fuel, although deeper investigations need to be performed in order to draw final conclusions. Particularly, at least from the neutronic point of view, the influence of Th percentage on the reactivity coefficients as well as on the delayed neutron fraction should be determined. Thus, at the moment it is possible to state that some optimized Th percentage in the initial $\mathrm{Pu} / \mathrm{Th}$ fuel could be suggested on the basis of the aim we are trying to reach.

(i) If we aim at Pu reducing, a Pu fertile-free fuel or a Th concentration $\sim 20 \%$ has to be adopted (Figure 19), because these fuels allow us to reach the highest burnup and the highest $\mathrm{Pu}$ consumption with a single irradiation cycle.

(ii) If we aim at maximising the natural resource exploitation (i.e., of both Th and U), Th content has to be around $67.5 \%$.

(iii) In any case, there does not seem to be any advantages in inserting more than $70 \%$ of Th in the fresh fuel (higher initial reactivity to be controlled, higher content of heavier elements, shorter cycle length, smaller consumption of the driver fuel).

This work, although quite deep, has to be considered not completed; so it needs of some further work. Looking at the future developments of these research, in order to have a complete knowledge of the analyzed problem, it would be necessary to evaluate the following:

(i) reactivity coefficients,

(ii) short- and long-term radiotoxicity evolution,

(iii) materials behaviour and compatibility in the analyzed cases (e.g., under high fluence, at high temperature, etc.),

(iv) fuel cycles in the frame of the energetic scenarios (taking into account also environmental and economical aspects),

(v) nonproliferation issues.

\section{Abbreviations}

AVR: $\quad$ Arbeitsgemeinschaft Versuch Reaktor

BG: $\quad$ Breeding Gain

BOC: $\quad$ Begin Of Cycle

BWR: Boiling Water Reactor

CEA: $\quad$ Commissariat à l'Énergie Atomique

CP: $\quad$ Coated Particle

DIMNP: Dipartimento di Ingegneria Meccanica, Nucleare e della Produzione

DRAGON: European Prototype HTGR at Winfrith in England built and operated by UKAEA

DU: $\quad$ Depleted Uranium

EFPD: $\quad$ Effective Full Power Days

EOC: $\quad$ End Of Cycle

EURATOM: European Atomic Energy Community

FIMA: $\quad$ Fission per Initial Metal Atom

FP6: $\quad$ 6th Framework Program

FP: $\quad$ Fission Products

FZJ: $\quad$ ForschungsZentrum Jülich

GCFR: $\quad$ Gas Cooled Fast Reactor

GIF: Generation IV International Forum

HEU: Highly Enriched Uranium

HLW: $\quad$ High Level Waste

HM: $\quad$ Heavy Metal (Actinides)

HTGR: $\quad$ High Temperature Gas cooled Reactor

HTR: $\quad$ High gas Temperature Reactor

LEU: $\quad$ Low Enriched Uranium

LMFBR: Liquid Metal Fast Breeder Reactor

LOMBT: Level Of Mine Balancing Time

LWR: Light Water Reactor

MA: $\quad$ Minor Actinides

MC: $\quad$ Monte Carlo

MCNP: A general Monte Carlo N-Particle transport

MOX: code, Version 5

MSR: $\quad$ Molten Salt Reactor

NEC: $\quad$ Nuclear Energy Centre

PBMR: $\quad$ Pebble Bed Modular Reactor

PCU: $\quad$ power conversion system

PUMA: $\quad$ European project on Plutonium and Minor Actinides management in THTR

PWR: $\quad$ Pressurized Water Reactor

RG: $\quad$ Reactor Grade

SEU: Slightly Enriched Uranium

SME: $\quad$ Small and Medium Enterprises

SNF: $\quad$ Spent Nuclear Fuel

THTR: $\quad$ Thorium High Temperature Reactor

TRISO: TRiple ISOtropic Coated Particles

TRU: TRans-Uranics

VHTR: Very High Temperature Reactor

WG: Weapon Grade

WWER: Russian pressurized light water reactor.

\section{Acknowledgments}

The work presented in this paper was partly funded by the European Union Sixth Framework Program, under contracts PuMA and RAPHAEL. First of all the authors want to thank 
Dr. J. C. Kuijper, Dr. B. Petrov, and Dr. K. Bakker of NRG, for useful information about HTRs' fuel composition and the chemical behaviour of the elements analysed in the fuel proposed in this article. They want also to thank Professor G. Forassassi for his support and Professor J. L. Kloosterman for many interesting suggestions.

\section{References}

[1] International Atomic Energy Agency, "Thorium based fuel options for the generation of electricity," IAEA-TECDOC1155, May 2000.

[2] M. Benedict, T. H. Pigford, and H. W. Levi, Nuclear Chemical Engineering, McGraw-Hill, New York, NY, USA, 2nd edition, 1981.

[3] http://www.puma-project.eu.

[4] N. Cerullo, D. Bufalino, G. Forasassi, G. Lomonaco, P. Rocchi, and V. Romanello, "An additional performance of HTRS: the waste radiotoxicity minimisation," Radiation Protection Dosimetry, vol. 115, no. 1-4, pp. 122-125, 2005.

[5] N. Cerullo, D. Bufalino, G. Forasassi, G. Lomonaco, P. Rocchi, and V. Romanello, "The capabilities of htrs to burn actinides and to optimize plutonium exploitation," in Proceedings of the 12th International Conference on Nuclear Engineering (ICONE '04), vol. 1, pp. 495-501, Arlington, Va, USA, April 2004.

[6] Thorium Report Committee, "Thorium as an energy source-Opportunities for Norway," January 2008, http://www.ect2008.com/publish_files/Kara.pdf.

[7] International Atomic Energy Agency, "Potential of thorium based fuel cycles to constraint plutonium and reduce long lived waste toxicity," IAEA-TECDOC-1349, April 2003.

[8] W. Chernock and K. E. Horton, "Status of liquid metal cooled fast reactor development in the USA," IAEA-TECDOC-791, Vienna, 1995.

[9] International Atomic Energy Agency, "Thorium fuel utilization: options and trends," IAEA-TECDOC-1319, November 2002.

[10] M. W. Rosenthal, P. W. Haubenreich, and R. B. Brigge, "The development status of Molten-Salt Breeder Reactor," OAK Ridge National Laboratory, August 1972.

[11] L. Mathieu, D. Heuer, E. Merle-Lucotte, et al., "Possible configurations for the thorium molten salt reactor and advantages of the fast nonmoderated version," Nuclear Science \& Engineering, vol. 161, no. 1, pp. 78-89, 2009.

[12] H. J. Rütten and K. A. Haas, "Research on the incineration of plutonium in a modular HTR using thorium-based fuel," Nuclear Engineering and Design, vol. 195, no. 3, pp. 353-360, 2000.

[13] H. Chang, Y. Yang, X. Jing, and Y. Xu, “Thorium-based fuel cycles in the modular high temperature reactor," Tsinghua Science and Technology, vol. 11, no. 6, pp. 731-738, 2006.

[14] E. Mulder and E. Teuchert, "Characteristics of a different fuel cycle in a PBMR-400 for burning reactor grade plutonium," Nuclear Engineering and Design, vol. 238, no. 11, pp. 28932897, 2008.

[15] J. C. Kuijper, E. Bomboni, N. Cerullo, et al., "Pu and MA management in thermal HTGRs-impact at fuel, reactor and fuel cycle levels," in Proceedings of the 4th International Topical Meeting on High Temperature Reactor (HTR '08), Washington, DC, USA, September 2008.

[16] H. J. Rütten and K. A. Haas, "Incineration of LWR-Plutonium (1. Generation and 2. Generation) in a Modular HTR using Thorium-based Fuel," HTR-N-02/05-D-3.2.2, 2004.
[17] E. Bomboni, N. Cerullo, and G. Lomonaco, "EPEME, Error in PEbble Modelling Evaluation code," NT-009(2008), Department of Mechanics, Nuclear and Production Engineering (DIMNP), Pisa, Italy, 2008.

[18] X-5 Monte Carlo Team, "MCNP_a general Monte Carlo Nparticle transport code," Version 5, October 2005.

[19] O. Cabellos, "Processing of the JEFF-3.1 cross section library into a continuous energy Monte Carlo radiation transport and criticality data library," OECD NEA Data Bank, May 2006, NEA/NSC/DOC(2006)18, http://www.nea.fr/abs/html/nea-1768.html.

[20] C. Pohl, "Additional calculations for fuel compositions of $\mathrm{PuO} 2$ and $\mathrm{ThO} 2$ in the PBMR-PUMA pebble bed high temperature reactor," PUMA, Work Package 1, Deliverable D123, August 2009.

[21] E. Fridman, E. Shwageraus, and A. Galperin, "Implementation of multi-group cross-section methodology in BGCore MCdepletion code," in Proceedings of the International Conference on the Physics of Reactors (PHYSOR '08), Interlaken, Switzerland, September 2008. 

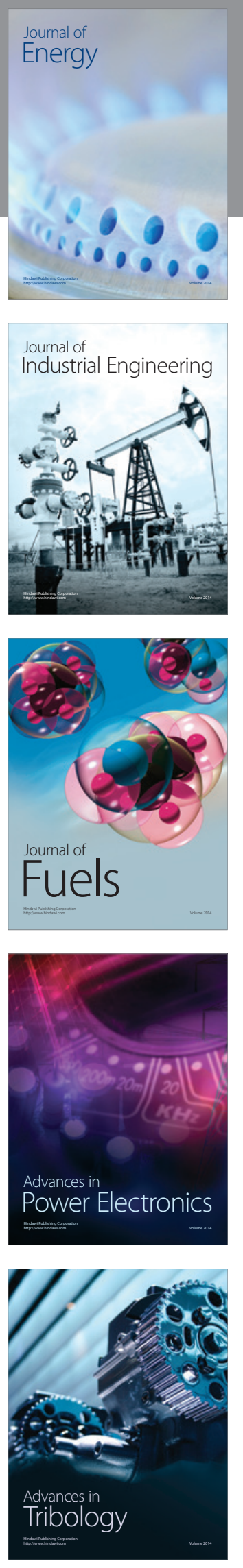
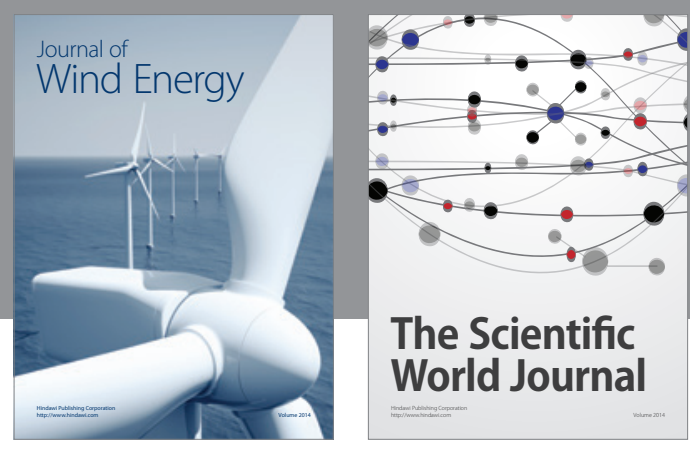

The Scientific World Journal

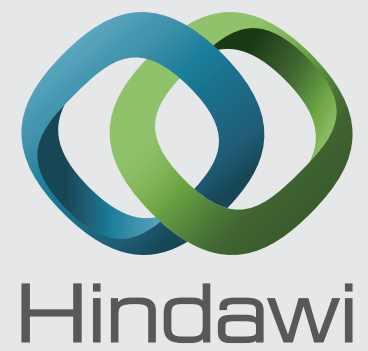

Submit your manuscripts at http://www.hindawi.com
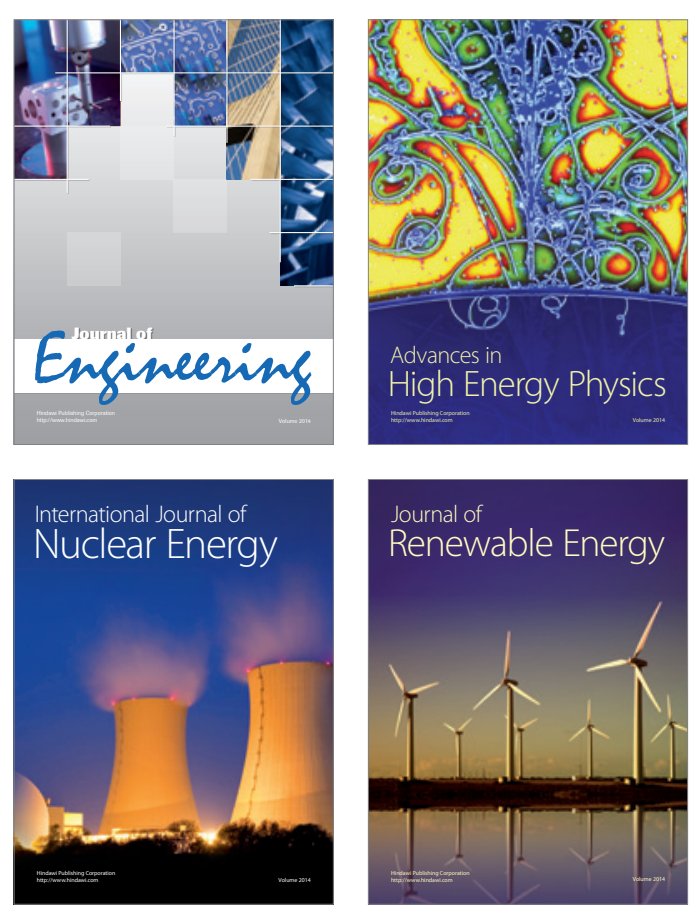

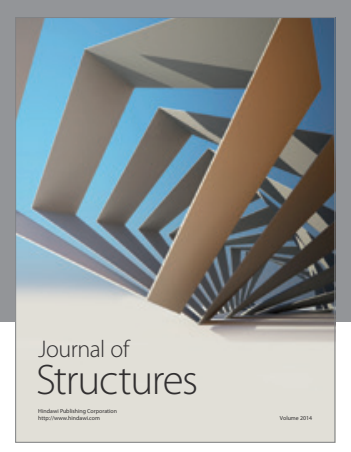

Rotating
Mechinery
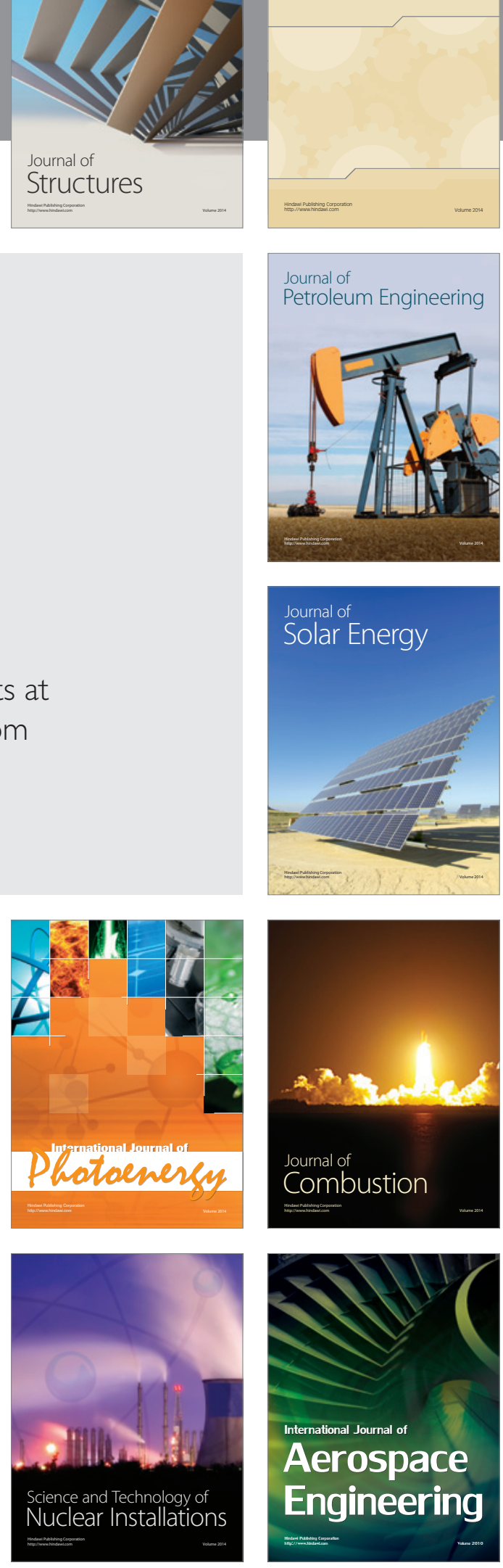